
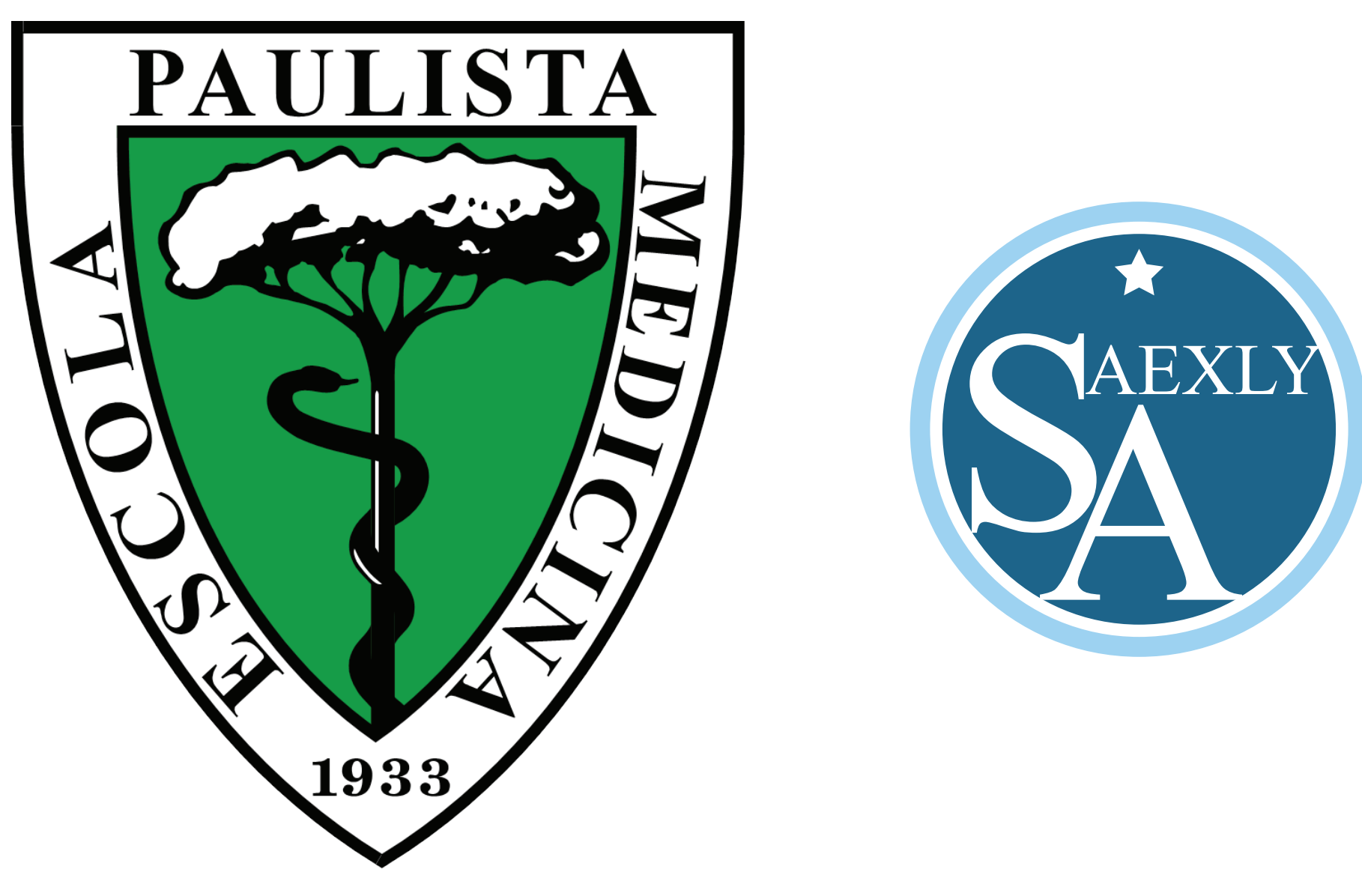

Sobre o Curso:

O Curso de Mestrado Profissional em Ciência, Tecnologia e Gestão Aplicadas à Regeneração Tecidual da UNIFESP tem por objetivo formar profissionais qualificados para o mercado de trabalho, capazes de utilizar a pesquisa para agregar valor a suas atividades, transferindo conhecimento técnico e científico para o mercado, para as empresas, para o setor público e para a sociedade como um todo.

\title{
O uso da tecnologia na gestão informatizada em serviços de nutrição hospitalar.
}

\author{
Autoras: \\ Weruska Davi Barrios, Vanessa Yuri Suzuki, Christiane Steponavicius Sobral, Denise Nicodemo, Lydia Masako Ferreira
}

\section{Introdução:}

Ferramentas como a internet, softwares e aplicativos já vem sendo usadas como um veículo pelos profissionais da área da saúde. A gestão de indicadores dentro das instituições hospitalares vem tomando lugar de destaque e se consolidando em forma de protocolos institucionais e multiprofissionais, para a melhoria contínua da assistência ao paciente, identificando pontos críticos, padronizando medidas preventivas e planos de contingências, e por fim, interferindo na contenção de perdas e danos não só para os pacientes, mas também para os profissionais e os serviços de saúde. A segurança do paciente pode se beneficiar com o uso da tecnologia minimizando erros e contribuindo para um gerenciamento de risco mais efetivo, prevenindo eventos adversos e elevando o cuidado prestado ao paciente hospitalizado. Monitorar indicadores nutricionais do paciente internado e intervir precocemente tem grande impacto não apenas na melhora do seu estado nutricional, como também no custo da internação.

\section{Objetivo:}

O objetivo deste estudo foi realizar uma revisão crítica sobre a gestão informatizada de indicadores em serviços de nutrição hospitalar associado ao uso de inovações como Design Thinking.

\section{Metodologia:}

Foi realizado um levantamento utilizando a base de dados Pubmed com período entre 2000 a 2017, utilizando os descritores: Informática em saúde, Serviço hospitalar de Nutrição, Segurança do paciente, Gestão da informação, além do termo Design Thinking como termo livre pesquisado em provedores de busca Google ${ }^{\circledR}$ Acadêmico.

\section{Resultados e Conclusão:}

Destacaram-se 17 artigos que respondiam ao objetivo proposto, incluídos no estudo.

Écrescente o uso de ferramentas de tecnologia para melhorara assistência ao paciente em instituições hospitalares. Hospitais e Instituições de Saúde armazenam e trabalham com um grande volume de dados, sejam eles de etiologia clínica, de informação pregressa do paciente e de sua evolução intrahospitalar. Este conteúdo rico normalmente se encontra armazenado em diferentes sistemas operacionais, que podem não ter a mesma linguagem e com isso se tornam impossibilitados de trocare usaresta informação dentro de um contexto de melhoria para o paciente. A Nutrição Hospitalar tem um impacto fundamental na terapêutica deste paciente quando bem monitorada. Associar o uso de tecnologias ao monitoramento nutricional dos pacientes incluindo os indicadores nutricionais pode facilitar a visão da gestão e da equipe multiprofissional envolvida na atenção ao cuidado, sendo uma importante ação na segurança do paciente. 